J. Dairy Sci. 95:2505-2512

http://dx.doi.org/10.3168/jds.2011-4908

(C) American Dairy Science Association ${ }^{\circledR}, 2012$.

\title{
A field trial on the effect of propylene glycol on displaced abomasum, removal from herd, and reproduction in fresh cows diagnosed with subclinical ketosis
}

\author{
J. A. A. McArt, ${ }^{*}$ D. V. Nydam, ${ }^{* 1}$ and G. R. Oetzel† \\ *Department of Population Medicine and Diagnostic Sciences, College of Veterinary Medicine, Cornell University, Ithaca, NY 14853 \\ †School of Veterinary Medicine, University of Wisconsin, Madison 53706
}

\begin{abstract}
The purpose was to determine the effect of oral propylene glycol (PG) administration in fresh cows diagnosed with subclinical ketosis (SCK). Measured outcomes were development of displaced abomasum (DA) and removal from herd in the first $30 \mathrm{~d}$ in milk (DIM), conception to first service, and time to conception within 150 DIM. Cows from 4 freestall dairy herds (2 in New York and 2 in Wisconsin) were each tested 6 times for SCK from 3 to 16 DIM on Mondays, Wednesdays, and Fridays using the Precision Xtra meter (Abbott Laboratories, Abbott Park, IL). Subclinical ketosis was defined as a blood $\beta$-hydroxybutyrate concentration of 1.2 to $2.9 \mathrm{mmol} / \mathrm{L}$. Cows with SCK were randomized to treatment group (oral PG) or untreated control group (no PG); treatment cows were orally drenched with 300 $\mathrm{mL}$ of $\mathrm{PG}$ once daily from the day they tested 1.2 to $2.9 \mathrm{mmol} / \mathrm{L}$ until the day they tested $<1.2 \mathrm{mmol} / \mathrm{L}$. Mixed effects multivariable Poisson regression was used to assess the effect of PG on DA, removal from herd, and conception to first service; a semiparametric proportional hazards model was used to evaluate the daysto-conception outcome. A total of 741 of 1,717 (43.2\%) eligible enrolled cows had at least $1 \beta$-hydroxybutyrate test of 1.2 to $2.9 \mathrm{mmol} / \mathrm{L}$. Of these, 372 were assigned to the PG treatment group and 369 to the control group. Thirty-nine cows (5.3\%) developed a DA after testing positive for SCK and 30 cows $(4.0 \%)$ died or were sold within the first 30 DIM. Based on risk ratios, control cows were 1.6 times more likely [95\% confidence interval $(\mathrm{CI})=1.3$ to 2.0$]$ to develop a DA and 2.1 times more likely (95\% CI $=1.2$ to 3.6$)$ to die or be sold than cows treated with PG. In addition, PG-treated cows were 1.3 times more likely (risk ratio $95 \% \mathrm{CI}=$ 1.1 to 1.5$)$ to conceive at first insemination than control cows in 3 of the herds. No difference was observed in
\end{abstract}

\footnotetext{
Received September 6, 2011.

Accepted January 5, 2012.

${ }^{1}$ Corresponding author: dvn2@cornell.edu
}

days to conception within 150 DIM between treatment groups (hazard ratio for $\mathrm{PG}$ cows $=1.1,95 \% \mathrm{CI}=$ 0.8 to 1.4 ), with a median time to conception of $100 \mathrm{~d}$ $(95 \% \mathrm{CI}=93$ to 111$)$ and $104 \mathrm{~d}(95 \% \mathrm{CI}=95$ to 114$)$ for PG-treated and control cows, respectively. These results show that intensive detection of SCK, followed by treatment of positive cows with oral PG decreased the risk of developing a DA or leaving the herd within the first 30 DIM and increased the risk of conception to first service.

Key words: dairy cow, ketosis, propylene glycol, cull

\section{INTRODUCTION}

During the transition from late gestation to early lactation, dairy cattle undergo a period of negative energy balance as the demands for milk synthesis cannot be met by feed intake (Bauman and Currie, 1980; Baird, 1982; Herdt, 2000). To adapt to this negative energy balance, among other mechanisms, cows mobilize lipid reserves, which circulate in the blood as NEFA. Circulating NEFA can then be used directly as a fuel source, metabolized in the liver to ketone bodies, or converted back into triglycerides. When the liver is overwhelmed by NEFA, ketone bodies are produced in excess and the cow becomes hyperketonemic (Herdt, 2000). The clinical signs associated with hyperketonemia may include a decrease in appetite, weight loss, and a decrease in milk production. In addition to clinical hyperketonemia, cows also suffer from subclinical ketosis (SCK), defined as an excess of circulating ketone bodies without clinical signs of ketosis (Andersson, 1988).

Cows that develop SCK are at an increased risk of additional postpartum diseases such as displaced abomasum (DA) and metritis (Duffield et al., 2009; Ospina et al., 2010a), which may increase their risk of removal from the herd during early lactation. Studies evaluating the effect of SCK on reproductive performance have provided differing results. In large studies by Walsh et al. (2007) and Ospina et al. (2010b), the concentration of blood BHBA and the duration of eleva- 
tion were negatively associated with pregnancy at first service, whereas a smaller study by Kessel et al. (2008) showed no difference in days from calving to conception or first-service conception rate between cows diagnosed with and without elevated blood BHBA.

The use of propylene glycol (PG) to treat clinical ketosis is not novel (Johnson, 1954; Maplesden, 1954); it is known to be anti-ketogenic by increasing plasma glucose concentrations through decreased peripheral tissue glucose demand (Kristensen and Raun, 2007) and lowering NEFA and liver triglyceride levels, resulting in a decrease in plasma BHBA concentrations (Sauer et al., 1973; Grummer et al., 1994; Chung et al., 2009). Although numerous trials have been conducted using various $\mathrm{PG}$ dosages, lactational stages of administration, routes of delivery, and length of treatment to test the effect of prophylactic PG administration (Studer et al., 1993; Miyoshi et al., 2001; Nielsen and Ingvartsen, 2004), no studies have reported the effect of PG on DA development or removal from herd in early lactation. However, the use of PG in decreasing the incidence of DA has been suggested as potentially beneficial (LeBlanc et al., 2005). It has also been postulated that the decrease in fat mobilization and hepatic ketogenesis after PG administration may have beneficial effects on reproduction (Nielsen and Ingvartsen, 2004). No studies have reported the effect of PG on cows with SCK except McArt et al. (2011).

The objective of this study was to determine the effect of oral PG administration on development of DA and removal from the herd in the first 30 DIM, conception to first service, and days to conception within 150 DIM in cows intensively monitored and diagnosed with SCK.

\section{MATERIALS AND METHODS}

\section{Study Population}

Data were collected from 2 dairy farms (farms A and B) in New York from May 18, 2010 until September 8, 2010 and from 2 dairy farms (farms C and D) in Wisconsin from June 11, 2010 until August 30, 2010. To be selected, farms had to meet the following criteria: milk at least 1,500 cows, have headlocks in fresh cow pens, use the farm management program Dairy Comp 305 (Valley Agricultural Software, Tulare, CA), and be willing to participate in the proposed ketosis testing and treatment protocol. Detailed information concerning farm management structure and nutrition has been reported previously (McArt et al., 2011); an overview of herd size, milk production, and reproductive and disease events can be found in Table 1.

\section{Data Collection and Study Design}

Enrollment into the study occurred at calving as described previously (McArt et al., 2011). Cows were tested from 3 to 16 DIM on Mondays, Wednesdays, and Fridays for ketosis using a Precision Xtra meter (Abbott Laboratories, Abbott Park, IL). The Precision Xtra meter is a hand-held device used to test blood BHBA concentrations; sensitivity and specificity compared with serum BHBA concentrations determined photometrically are 96 to $100 \%$ and 98 to $100 \%$, respectively, when using a cut-off value of $\geq 1.2 \mathrm{mmol} / \mathrm{L}$ (Iwersen et al., 2009; Konkol et al., 2009). Given this testing scheme, each cow was sampled 6 times, beginning at 3,4 , or 5 DIM and ending on 14,15 , or 16 DIM.

Table 1. Farm management features

\begin{tabular}{|c|c|c|c|c|}
\hline \multirow[b]{2}{*}{ Feature } & \multicolumn{4}{|c|}{ Herd } \\
\hline & A & B & $\mathrm{C}$ & $\mathrm{D}$ \\
\hline Size (cows) & 1,900 & 1,800 & 2,800 & 4,100 \\
\hline Avg. milk/cow per day (kg) & 41.8 & 41.8 & 39.4 & 35.3 \\
\hline Feeding system & TMR & TMR & TMR & TMR \\
\hline Monensin in transition diet $(\mathrm{g} / \mathrm{t})$ & 16 & 12 & 12 & - \\
\hline $\mathrm{VWP}^{1}(\mathrm{~d})$ & 50 & $\begin{array}{c}55 \text { for lactation } \geq 2 \\
67 \text { for lactation } 1\end{array}$ & 65 & 80 \\
\hline Pregnancy rate ${ }^{2}$ & 21 & 24 & 19 & 19 \\
\hline $\mathrm{DA} \operatorname{risk}^{3}(\%)$ & 3.2 & 2.7 & 2.6 & 2.9 \\
\hline Early removal risk ${ }^{4}(\%)$ & 3.3 & 3.5 & 4.1 & 7.3 \\
\hline Late removal risk $^{5}(\%)$ & 42.9 & 41.9 & 42.0 & 46.3 \\
\hline
\end{tabular}


Subclinical ketosis was defined as a BHBA concentration of 1.2 to $2.9 \mathrm{mmol} / \mathrm{L}$; clinical ketosis was defined as $\geq 3.0 \mathrm{mmol} / \mathrm{L}$ (Oetzel, 2004).

On farms $\mathrm{A}$ and $\mathrm{B}, 10 \mathrm{~mL}$ of blood was collected from the coccygeal vessels of each cow using a tube without anticoagulant and a 20-gauge $\times 2.54$-cm blood collection needle. On farms $\mathrm{C}$ and $\mathrm{D}$, approximately 0.5 $\mathrm{mL}$ of blood was collected from the coccygeal vessels using a 22 -gauge $\times 2.54$-cm needle and a 1 -mL syringe. Beta-hydroxybutyrate testing was completed according to Precision Xtra meter instructions and performed immediately after blood collection. A ketone strip was attached to the Precision Xtra meter until the add blood symbol appeared on the meter display. The lot number of the inserted ketone strip was then checked to ensure matching with the lot number displayed on the meter. For each cow test, a drop of blood was applied to the ketone test strip test chamber; the meter indicated when the chamber was full. After $10 \mathrm{~s}$, the BHBA concentration was displayed on the meter and the value recorded.

All testing of cows for SCK from 3 to 16 DIM was completed by the research team during the study. Cows with BHBA concentrations of 1.2 to $2.9 \mathrm{mmol} / \mathrm{L}$ were sequentially randomized to treatment group (oral PG drench) or untreated control group (no PG) after their first SCK-positive test. Randomization to treatment group for the first cow on each farm was completed in Excel (Microsoft Corp., Redmond, WA) using the random number function. Cows assigned to treatment were orally drenched with $300 \mathrm{~mL}$ PG (E. H. Wolf \& Sons Inc., Green Bay, WI) once daily from the day they tested $\geq 1.2 \mathrm{mmol} / \mathrm{L}$ until the day they tested $<1.2$ mmol/L or reached 17 DIM. Administration of a 300$\mathrm{mL}$ volume was chosen, as it is a common dose used on farms and delivers approximately $310 \mathrm{~g}$ of PG. Drenching on farms A and B was completed by the research team; drenching on farms $\mathrm{C}$ and $\mathrm{D}$ was completed by on-farm personnel. Cows with BHBA concentrations of $\geq 3.0 \mathrm{mmol} / \mathrm{L}$ were treated by on-farm personnel per farm protocol for cows diagnosed with ketosis.

Cows were excluded from the study if their previous days carried calf was less than $260 \mathrm{~d}$, if they died or were sold before their first BHBA test, if they were diagnosed and treated by the farm for ketosis before their first BHBA test, if they tested $\geq 3.0 \mathrm{mmol} / \mathrm{L}$ before testing 1.2 to $2.9 \mathrm{mmol} / \mathrm{L}$, or for lack of proper identification. Additionally, cows remaining in the herd through 16 DIM were excluded if they had fewer than 5 BHBA tests. Further data collected included parity, DA, metritis, sold and died events, conception to first service, and DIM at conception. Displaced abomasa, cows died, cows sold, and pregnancy outcomes were exported throughout the study period from each farm's Dairy Comp 305 program.

A proposal was reviewed and approved by the Cornell University Institutional Animal Care and Use Committee (Ithaca, NY; \#2008-0099) and the University of Wisconsin Institutional Animal Care and Use Committee (Madison; \#V01479-0-05-10). All farms were asked to sign a consent form agreeing to the proposed testing and treatment protocol and were given a document containing information on disease definitions, including clinical milk fever, retained placenta, metritis, displaced abomasum, and clinical ketosis.

\section{Statistical Analysis}

Descriptive statistics were generated with the FREQ procedure of SAS (SAS Institute Inc., Cary, NC); difference in parity between the 2 treatment groups was analyzed using a chi-squared test. The effect of PG in SCK-positive cows on DA development, removal from herd, and conception to first service was analyzed using mixed effects multivariable Poisson regression with the GENMOD procedure of SAS (Frome and Checkoway, 1985; Spiegelman and Hertzmark, 2005). For the model evaluating DA development, SCK-positive cows developing a DA before their first SCK-positive test were removed from the analysis. The potential confounding variables lactation group (lactation 1 , lactation 2 , and lactation $\geq 3$ ) and metritis were offered to the models (the variable DA was also offered to the model concerning removal from herd) as independent variables in addition to PG treatment. The variable herd was entered as a random effect in the DA and removal models. Due to large differences in voluntary waiting period (VWP), conception to first service, and breeding strategy (inseminating many cows twice) on farm $\mathrm{D}$, the variable herd was tested as a fixed effect in the conception-to-first-service model; an offset term was used to adjust for the difference in VWP for each herd. Independent variables were removed by manual backward stepwise elimination if their contrast estimate was considered statistically nonsignificant $(P>0.10)$ and biologically not important. Statistical significance of the variable herd in the conception-to-first-service model led to further analysis of conception by herd. Due to biologically plausible explanations for a change in outcome direction compared with the other 3 farms, farm D was excluded from both conception-to-firstservice and time-to-conception analyses. The variable herd was then re-entered into the conception-to-firstservice model as a random effect to account for the unmeasured variations between the remaining 3 herds. The effect of PG on time to conception was analyzed 
Table 2. Herd incidence during the study period of subclinical ketosis (SCK) from 3 to 16 DIM, displaced abomasum (DA) in the first 30 DIM, and removal from herd in the first 30 DIM for all 1,717 Holstein cows

\begin{tabular}{lcll}
\hline Herd & SCK $(\%)$ & DA $(\%)$ & $\begin{array}{c}\text { Early } \\
\text { removal }(\%)\end{array}$ \\
\hline Farm A & $40.4(\mathrm{n}=143)$ & $2.0(\mathrm{n}=7)$ & $2.3(\mathrm{n}=8)$ \\
Farm B & $26.4(\mathrm{n}=106)$ & $2.0(\mathrm{n}=8)$ & $3.0(\mathrm{n}=12)$ \\
Farm C & $40.9(\mathrm{n}=119)$ & $1.7(\mathrm{n}=5)$ & $7.2(\mathrm{n}=21)$ \\
Farm D & $55.7(\mathrm{n}=373)$ & $3.3(\mathrm{n}=22)$ & $8.8(\mathrm{n}=59)$ \\
\hline
\end{tabular}

by a semiparametric proportional hazards model (Cox, 1972) using the PHREG procedure of SAS. The time series variable for the model was the number of days from calving until conception within 150 DIM. Censoring variables were used to identify cows that conceived from cows that were either removed from the herd or did not conceive by 150 DIM. Independent variables offered to the model included PG treatment, lactation group, and herd. Independent variables and their respective interaction terms were manually removed by backward stepwise elimination if considered statistically nonsignificant $(P>0.10)$ and biologically not important. Proportional hazards assumptions were verified by evaluating the time-dependent covariates (Allison, 1995); noninformative censoring was evaluated using sensitivity analysis. A Kaplan-Meier analysis (Kaplan and Meier, 1958) using only the PG treatment variable was completed using the LIFETEST procedure of SAS to determine median days from calving to conception for both treatment groups.

\section{RESULTS}

\section{Descriptive Statistics}

Of the 1,717 eligible enrolled cows, 741 (43.2\%) were diagnosed with SCK and randomized, with 372 cows receiving PG treatment and 369 control cows. The control group was composed of 106, 97, and 166 cows in lactation 1,2 , and $\geq 3$, respectively $($ median $=2$ ); the treatment group contained 109 cows in lactation 1, 92 in lactation 2 , and 171 in lactation $\geq 3($ median $=2$ ). No difference in parity between the 2 groups $(P=0.89)$ was observed. Table 2 shows the incidence of SCK, DA, and early lactation removals by herd.

\section{Displaced Abomasum}

In the first 30 DIM, 3 of 976 SCK-negative cows (0.3\%) developed a DA and 39 of 739 cows (5.3\%) developed a DA after testing positive for SCK (2 cows developed a DA before testing positive for SCK and were excluded from the analysis). For the SCK-positive cows, $24(6.5 \%)$ of the control cows developed a DA compared with $15(4.0 \%)$ of the PG-treated cows. Table 3 shows DA incidence in SCK-positive cows by herd and treatment group. Control cows were 1.6 times more likely [risk ratio $(\mathbf{R R}) 95 \% \mathrm{CI}=1.3$ to $2.0, P<$ $0.001]$ to develop a DA than cows treated with PG. The final regression model included only the PG treatment variable with herd as a random effect. The final model estimate is in Table 4.

\section{Early Lactation Removals}

In the first 30 DIM, 18 of $976(1.8 \%)$ SCK-negative cows and 30 of 741 cows $(4.1 \%)$ that tested positive for SCK were removed from the herd. For the SCK-positive cows, $20(5.4 \%)$ of the control cows were removed before 30 DIM compared with $10(2.7 \%)$ of the PG-treated cows. Table 3 shows the incidence of removal from the herd in the first $30 \mathrm{~d}$ by herd and treatment group. Control cows were 2.1 times more likely (RR 95\% CI $=1.2$ to $3.6, P=0.01)$ to die or be culled than cows treated with PG. The final regression model included only the PG treatment variable with herd as a random effect. The final model estimate is in Table 4.

\section{Conception to First Service and Time to Conception}

Table 5 shows conception to first service and median days to conception by herd and treatment group. Cows in farm D were removed from analysis of reproductive outcomes due to major differences in VWP and firstservice breeding protocols. Of the remaining 3 herds, 907 cows had data concerning conception at first service; 241 of 603 (40.0\%) SCK-negative cows and 123 of $304(40.5 \%)$ SCK-positive cows conceived to first service. Of the SCK-positive cows, 52 of 148 (35.1\%) control cows conceived at their first service compared with 71 of 156 (45.5\%) PG-treated cows. Cows treated with PG were 1.3 times more likely (RR $95 \% \mathrm{CI}=1.1$ to $1.5, P=0.002)$ to conceive than control cows. The

Table 3. Herd incidence of displaced abomasum (DA) and removal from herd in the first 30 DIM for 741 Holstein cows diagnosed with subclinical ketosis between 3 and 16 DIM and randomized to treatment with propylene glycol (PG) or without PG (control)

\begin{tabular}{lcccc}
\hline & \multicolumn{5}{c}{ Herd } \\
\cline { 2 - 5 } Item & $\mathrm{A}$ & $\mathrm{B}$ & $\mathrm{C}$ & $\mathrm{D}$ \\
\hline DA (\%) & & & & \\
Control & 4.3 & 9.3 & 5.2 & 7.1 \\
PG & 4.1 & 3.8 & 3.3 & 4.2 \\
Removal (\%) & & & & \\
Control & 5.7 & 3.7 & 3.4 & 6.5 \\
PG & 1.4 & 0.0 & 1.6 & 4.2 \\
\hline
\end{tabular}


Table 4. Estimates for 3 final Poisson regression models showing risk ratios (RR) for 741 Holstein cows with at least 1 positive test for subclinical ketosis from 3 to 16 DIM randomly assigned to propylene glycol treatment $(\mathrm{n}=372)$ or control $(\mathrm{n}=369)^{1}$

\begin{tabular}{lccccc}
\hline Model & Estimate & $\mathrm{SE}^{2}$ & $P$-value & $\mathrm{RR}$ & $95 \% \mathrm{CI}^{4}$ \\
\hline DA & 0.47 & 0.11 & $<0.0001$ & 1.6 & 1.3 to 2.0 \\
CULL & 0.72 & 0.29 & 0.01 & 2.1 & 1.2 to 3.6 \\
PREG & 0.27 & 0.09 & 0.002 & 1.3 & 1.1 to 1.5 \\
\hline
\end{tabular}

${ }^{1}$ The 3 outcomes modeled were 1) development of a displaced abomasum (DA) within 30 DIM, 2) removal from herd (CULL) within 30 DIM, and 3) conception to first service (PREG).

${ }^{2} \mathrm{SE}=$ standard error for estimate.

${ }^{3} P$-value reported for estimate.

${ }^{4}$ Confidence interval for risk or hazard ratio.

final regression model included only the PG treatment variable with herd as a random effect. The estimate for the final conception-to-first-service model is in Table 4.

Farms A, B, and C had 904 cows with data concerning pregnancy status at 150 DIM; 496 of 601 (82.5\%) SCK-negative cows and 237 of 303 (78.2\%) SCK-positive cows were pregnant. Of the SCK-positive cows, 115 of $148(77.7 \%)$ control cows and 122 of 155 (78.7\%) PG-treated cows were pregnant. No difference was observed in days to conception within 150 DIM between treatment groups (hazard ratio for $\mathrm{PG}$ cows $=$ $1.1,95 \% \mathrm{CI}=0.8$ to $1.4, P=0.70)$, with a median time to conception of $100 \mathrm{~d}(95 \% \mathrm{CI}=93$ to 111$)$ and $104 \mathrm{~d}$ $(95 \% \mathrm{CI}=95$ to 114$)$ for PG-treated and control cows, respectively. The final model concerning the effect of PG on time to pregnancy included the variables PG treatment, herd, and lactation group. The final model estimates are in Table 6.

\section{DISCUSSION}

The reported study was conducted to determine the effects of oral PG administration on development of DA and removal from the herd in the first 30 DIM, conception to first service, and days to conception within 150 DIM in cows diagnosed with SCK. Results show that cows treated with oral PG were less likely to develop a DA, less likely to be removed from the herd in the first 30 DIM, and more likely to conceive to first service than control cows; no difference existed in time to conception within 150 DIM between the 2 groups. Whereas these results derive from large, freestall, TMR-fed dairies and are, thus, more likely to have external validity under these conditions, the PG treatment was on an individual-cow basis. It is, therefore, biologically plausible that the benefits of PG pertain to cows managed in a variety of environments; however, the physiology and ecology of ketosis may be different in componentfed herds. In these herds, ketogenesis may be more related to a mismatch between energy expenditure and consumption slightly later in lactation than to events associated with lipolysis in the dry period. It remains undetermined from this study if PG would be beneficial to cows managed in these conditions.

The choice to compare PG-treated cows to an untreated control group rather than a group receiving a placebo solution was made to include the stress of handling and dosing in the PG response. On farms A and $\mathrm{B}$, because the treatments were given by the research team, no potential existed for management bias from farm employees, as they were not aware of which cows received treatment. Although PG-treated cows on farms C and D were dosed by farm personnel, they were dosed under the direction and supervision of the research team at the time of testing. Although not blinded to treatment, it is unlikely that any management

Table 5. Conception risk and median time to conception (95\% CI) for 741 Holstein cows with at least 1 positive test for subclinical ketosis from 3 to 16 DIM randomly assigned to propylene glycol (PG) treatment $(\mathrm{n}=372)$ or control $(\mathrm{n}=369)$

\begin{tabular}{lcccc}
\hline & \multicolumn{3}{c}{ Herd } \\
\cline { 2 - 5 } Item & $\mathrm{A}$ & $\mathrm{B}$ & $\mathrm{C}$ & $\mathrm{D}$ \\
\hline Conception risk (\%) & & & \\
$\quad$ Control & 32.8 & 43.2 & 50.0 & 80.4 \\
PG & 42.9 & 44.2 & & 76.6 \\
Days to conception & $106(94$ to 123$)$ & $95(82$ to 104$)$ & $118(96$ to 146$)$ & 112 (103 to 123$)$ \\
Control & $100(83$ to 121$)$ & $101(95$ to 111$)$ & $100(78$ to 134$)$ & 105 (92 to 111$)$ \\
PG & & & & \\
\hline
\end{tabular}


Table 6. Covariate estimates and hazard ratios (HR) for Cox proportional analysis of time to conception within 150 DIM for 303 Holstein cows with at least 1 positive test for subclinical ketosis from 3 to 16 DIM randomly assigned to propylene glycol treatment $(\mathrm{n}=372)$ or control $(\mathrm{n}=369)^{1}$

\begin{tabular}{|c|c|c|c|c|c|}
\hline Covariate & Estimate & $\mathrm{SE}^{2}$ & $P$-value ${ }^{3}$ & $\mathrm{HR}$ & $95 \% \mathrm{CI}^{4}$ \\
\hline $\begin{array}{l}\text { PG } \\
\text { LACT }\end{array}$ & 0.05 & 0.13 & 0.70 & 1.1 & 0.8 to 1.4 \\
\hline 1 & 0.27 & 0.15 & 0.08 & 1.3 & 1.0 to 1.8 \\
\hline 2 & -0.04 & 0.17 & 0.83 & 1.0 & 0.7 to 1.3 \\
\hline$\geq 3^{5}$ & - & - & - & - & - \\
\hline \multicolumn{6}{|l|}{ Herd } \\
\hline Farm A & 0.24 & 0.16 & 0.14 & 1.3 & 0.9 to 1.7 \\
\hline Farm B & 0.54 & 0.18 & 0.002 & 1.7 & 1.2 to 2.4 \\
\hline Farm $\mathrm{C}^{5}$ & - & - & - & - & - \\
\hline \multicolumn{6}{|c|}{$\begin{array}{l}{ }^{1} \text { Independent variables offered to the model included propylene glycol (PG) treatment, lactation (LACT) } \\
\text { herd. } \\
{ }^{2} \mathrm{SE}=\text { standard error for estimate. } \\
{ }^{3} \mathrm{P} \text {-value reported for estimate. } \\
{ }^{4} \text { Confidence interval for hazard or risk ratio. }\end{array}$} \\
\hline
\end{tabular}

bias subsequently occurred. In addition, all measured outcomes were objective and numerical. Sequential randomization was chosen for allocation to treatment group over other randomization methods to ensure an almost equal number of cows assigned to the PG and control group by day. In the studied on-farm settings, where environmental factors such as heat index and delayed feedings could potentially affect the outcome, it was deemed important to have cows in both the PG treatment and control groups be equally exposed to these daily variations.

Administration of oral PG to SCK-positive cows decreased the risk of developing a DA, as control cows were 1.6 times more likely to develop a DA than cows treated with PG. No other studies have analyzed the effect of PG on DA development. Pickett et al. (2003) reported the number of cows developing a DA when administered water, $\mathrm{PG}$, or a combination of $\mathrm{PG}$ and fat during the first $3 \mathrm{~d}$ postpartum, but acknowledged that the sample size was too small to draw conclusions on an overall treatment effect.

In addition to having an increased risk of developing a DA, SCK-positive control cows were 2.1 times more likely to be removed from the herd within the first 30 DIM than PG-treated cows, at a 5.4 and $2.7 \%$ early removal rate, respectively. In fact, administration of PG to SCK-positive cows decreased the rate of removal to that of their non-ketotic herdmates at 2.7 and $1.8 \%$, respectively $(P=0.20)$. Possible reasons that $P G$ administration decreases removal risk in cows with SCK include its ability to assist in resolution of ketosis, to help prevent clinical ketosis, and to improve milk yield in cows diagnosed with SCK (McArt et al., 2011) as well as its ability to help prevent DA development. No other studies have examined the effect of PG in cows with SCK on removal of cows from the herd.

During analysis of conception to first service, it was noted that the variable herd was very important with a low type 1 error risk. However, no important herd by treatment interaction occurred. Upon further stratification and examination by herd, it was discovered that the first-service conception risk on farm $\mathrm{D}$ was of a different magnitude and direction than that of the other 3 farms. Compared with these herds, the reproductive management on farm $\mathrm{D}$ was quite different, giving a plausible biological explanation for the difference in conception to first service. The cows on farm D had an extended VWP ( $80 \mathrm{~d}$ versus 50 to $67 \mathrm{~d}$ for the other 3 farms), and approximately $20 \%$ of cows were bred a second time, within $24 \mathrm{~h}$ of first insemination. Farm D was subsequently excluded from the analysis of both reproductive outcomes. Analyzing only the data from farms A, B, and C, a beneficial effect of PG was found concerning conception to first service, with PG-treated cows 1.3 times more likely to conceive to first service than control cows. However, no difference was found in time to conception within 150 DIM. It is hypothesized that the effect of PG on reproduction may be time dependent in that it affects cows earlier in lactation but its benefits diminish over time.

Although no studies have examined the effect of PG on reproduction in cows diagnosed with SCK, multiple studies report on the reproductive effects of PG when given prophylactically in early lactation, although with differing results. Hoedemaker et al. (2004) found no difference in first-service conception, pregnancy rate, time from first AI to conception, or days open for cows supplemented with PG in the feed from $13 \mathrm{~d}$ before 
expected calving until 12 d postpartum. Similarly, Castañeda-Gutiérrez et al. (2009) found no difference in time to first ovulation in multiparous cows after daily topdressing with PG from $21 \mathrm{~d}$ before expected calving until 21 d postpartum, nor did Lien et al. (2010) after oral administration of $500 \mathrm{~mL}$ of PG from $7 \mathrm{~d}$ prepartum to $30 \mathrm{~d}$ postpartum. Although no difference was found in days to first service, days open, or services per conception in both primiparous and multiparous cows by Miyoshi et al. (2001), oral administration of 500 $\mathrm{mL}$ of PG from 7 to 42 DIM did decrease the interval from calving until first ovulation from 44.5 to $32.3 \mathrm{~d}$. Chagas et al. (2007) also found a decreased interval from calving to first ovulation in heifers with poor body condition after being drenched with $250 \mathrm{~mL}$ of $\mathrm{PG}$ twice daily for 16 wk after parturition. However, these studies are difficult to compare with the current study because they either did not determine the ketosis status of the cows before giving PG or they administered PG in the diet instead of oral drench. No comparison can be made concerning time to first ovulation, as it was not measured in this study.

It is important to note that all final Poisson models, in addition to the random effect variable (herd) contained only the PG treatment variable. This suggests that PG treatment alone, across multiple outcomes, is an important factor in determining the risk of DA development and early removal from the herd in cows with SCK. The administration of PG to SCK-positive cows carries potential economic implications resulting from the decreased risk of DA development and removal from the herd in the first 30 DIM, as well as the increased risk of conception to first insemination. Further investigation is needed to determine the best testing and dosing scheme that is both economical and practical for management and labor purposes.

\section{CONCLUSIONS}

Intensive detection of SCK, followed by treatment of positive cows with oral PG, decreased the risk of developing a DA or leaving the herd within the first 30 DIM and had a positive effect on conception to first service in some herds.

\section{ACKNOWLEDGMENTS}

This study was funded, in part, by the US Department of Agriculture-National Research Initiative (USDA-NRI) and Boehringer Ingelheim Vetmedica Inc. (St. Joseph, MO). The authors thank Judith Alishauskas, Stephanie Brittin, Emily Bold, Mark Fagan, and Caitlin Jeffrey (Cornell University, Ithaca, NY), and
Lindley Reilly, Eric Rooker, Angela Niles, Tyler Franks, Catherine Bargren, Diego Calderon, Cristian Vergara, and Loïc Commun (University of Wisconsin, Madison) for their invaluable assistance with data collection, as well as the owners of the collaborating dairies for allowing us access to their cows and facilities on which to conduct this research.

\section{REFERENCES}

Allison, P. D. 1995. Survival Analysis using the SAS System: A Practical Guide. SAS Institute Inc., Cary, NC.

Andersson, L. 1988. Subclinical ketosis in dairy cows. Vet. Clin. North Am. Food Anim. Pract. 4:233-251.

Baird, G. D. 1982. Primary ketosis in the high-producing dairy cow: Clinical and subclinical disorders, treatment, prevention, and outlook. J. Dairy Sci. 65:1-10.

Bauman, D. E., and W. B. Currie. 1980. Partitioning of nutrients during pregnancy and lactation: A review of mechanisms involving homeostasis and homeorhesis. J. Dairy Sci. 63:1514-1529.

Castañeda-Gutiérrez, E., S. H. Pelton, R. O. Gilbert, and W. R. Butler. 2009. Effect of peripartum dietary energy supplementation of dairy cows on metabolites, liver function and reproductive variables. Anim. Reprod. Sci. 112:301-315.

Chagas, L. M., P. J. S. Gore, S. Meier, K. A. Macdonald, and G. A. Verkerk. 2007. Effect of monopropylene glycol on luteinizing hormone, metabolites, and postpartum anovulatory intervals in primiparous dairy cows. J. Dairy Sci. 90:1168-1175.

Chung, Y. H., C. M. Martinez, N. E. Brown, T. W. Cassidy, and G. A. Varga. 2009. Ruminal and blood responses to propylene glycol during frequent feeding. J. Dairy Sci. 92:4555-4564.

Cox, D. 1972. Regression models and life-tables. J. R. Stat. Soc., B $34: 187-220$

Duffield, T. F., K. D. Lissemore, B. W. McBride, and K. E. Leslie. 2009. Impact of hyperketonemia in early lactation dairy cows on health and production. J. Dairy Sci. 92:571-580.

Frome, E. L., and H. Checkoway. 1985. Epidemiologic programs for computers and calculators. Use of Poisson regression models in estimating incidence rates and ratios. Am. J. Epidemiol. 121:309 323.

Grummer, R. R., J. C. Winkler, S. J. Bertics, and V. A. Studer. 1994. Effect of propylene glycol dosage during feed restriction on metabolites in blood of prepartum Holstein heifers. J. Dairy Sci. $77: 3618-3623$

Herdt, T. H. 2000. Ruminant adaptation to negative energy balance. Influences on the etiology of ketosis and fatty liver. Vet. Clin. North Am. Food Anim. Pract. 16:215-230.

Hoedemaker, M., D. Prange, H. Zerbe, J. Frank, A. Daxenberger, and H. H. D. Meyer. 2004. Peripartal propylene glycol supplementation and metabolism, animal health, fertility, and production in dairy cows. J. Dairy Sci. 87:2136-2145.

Iwersen, M., U. Falkenberg, R. Voigtsberger, D. Forderung, and W. Heuwieser. 2009. Evaluation of an electronic cowside test to detect subclinical ketosis in dairy cows. J. Dairy Sci. 92:2618-2624.

Johnson, R. B. 1954. The treatment of ketosis with glycerol and propylene glycol. Cornell Vet. 44:6-21.

Kaplan, E. L., and P. Meier. 1958. Nonparametric estimation from incomplete observations. J. Am. Stat. Assoc. 53:457-481.

Kessel, S., M. Stroehl, H. H. Meyer, S. Hiss, H. Sauerwein, F. J. Schwarz, and R. M. Bruckmaier. 2008. Individual variability in physiological adaptation to metabolic stress during early lactation in dairy cows kept under equal conditions. J. Anim. Sci. 86:2903-2912.

Konkol, K., S. Godden, P. Rapnicki, and M. Overton. 2009. Validation of a rapid cow-side test for the measurement of blood betahydroxybutyrate in fresh cows. Page 190 in Proc. 42nd Annual 
Conf., Am. Assoc. of Bovine Pract., Omaha, NE. VM Publishing Co., Stillwater, OK.

Kristensen, N. B., and B. M. Raun. 2007. Ruminal and intermediary metabolism of propylene glycol in lactating Holstein cows. J. Dairy Sci. 90:4707-4717.

LeBlanc, S. J., K. E. Leslie, and T. F. Duffield. 2005. Metabolic predictors of displaced abomasum in dairy cattle. J. Dairy Sci. $88: 159-170$.

Lien, T. F., L. B. Chang, Y. M. Hong, and C. P. Wu. 2010. Effects of propylene glycol on milk production, serum metabolites, and reproductive performance during the transition period of dairy cows. Asian-australas. J. Anim. Sci. 23:372-378.

Maplesden, D. C. 1954. Propylene glycol in the treatment of ketosis. Can. J. Comp. Med. Vet. Sci. 18:287-293.

McArt, J. A. A., D. V. Nydam, P. A. Ospina, and G. R. Oetzel. 2011. A field trial on the effect of propylene glycol on milk yield and resolution of ketosis in fresh cows diagnosed with subclinical ketosis. J. Dairy Sci. 94:6011-6020. http://dx.doi.org/10.3168/ jds.2011-4463.

Miyoshi, S., J. L. Pate, and D. L. Palmquist. 2001. Effects of propylene glycol drenching on energy balance, plasma glucose, plasma insulin, ovarian function and conception in dairy cows. Anim. Reprod. Sci. 68:29-43.

Nielsen, N. I., and K. L. Ingvartsen. 2004. Propylene glycol for dairy cows: A review of the metabolism of propylene glycol and its effects on physiological parameters, feed intake, milk production and risk of ketosis. Anim. Feed Sci. Technol. 115:191-213.

Oetzel, G. R. 2004. Monitoring and testing dairy herds for metabolic disease. Vet. Clin. North Am. Food Anim. Pract. 20:651-674.
Ospina, P. A., D. V. Nydam, T. Stokol, and T. R. Overton. 2010a. Association between the proportion of sampled transition cows with increased nonesterified fatty acids and $\beta$-hydroxybutyrate and disease incidence, pregnancy rate, and milk production at the herd level. J. Dairy Sci. 93:3595-3601.

Ospina, P. A., D. V. Nydam, T. Stokol, and T. R. Overton. 2010b. Associations of elevated nonesterified fatty acids and $\beta$-hydroxybutyrate concentrations with early lactation reproductive performance and milk production in transition dairy cattle in the northeastern United States. J. Dairy Sci. 93:1596-1603.

Pickett, M. M., M. S. Piepenbrink, and T. R. Overton. 2003. Effects of propylene glycol or fat drench on plasma metabolites, liver composition, and production of dairy cows during the periparturient period. J. Dairy Sci. 86:2113-2121.

Sauer, F. D., J. D. Erfle, and L. J. Fisher. 1973. Propylene glycol and glycerol as a feed additive for lactating dairy cows: An evaluation of blood metabolite parameters. Can. J. Anim. Sci. 53:265-271.

Spiegelman, D., and E. Hertzmark. 2005. Easy SAS calculation for risk or prevalence ratios and differences. Am. J. Epidemiol. 162:199-200.

Studer, V. A., R. R. Grummer, S. J. Bertics, and C. K. Reynolds. 1993. Effect of prepartum propylene glycol administration on periparturient fatty liver in dairy cows. J. Dairy Sci. 76:2931-2939.

Walsh, R. B., J. S. Walton, D. F. Kelton, S. J. LeBlanc, K. E. Leslie, and T. F. Duffield. 2007. The effect of subclinical ketosis in early lactation on reproductive performance of postpartum dairy cows. J. Dairy Sci. 90:2788-2796. 